\title{
An examination of variability in offender residences across different spatial scales. A case study in Birmingham.
}

\author{
Samuel Langton $\dagger \quad$ Wouter Steenbeek $\quad$ Monsuru Adepeju $\dagger$
}

\begin{abstract}
Objectives This paper disentangles the degree of concentration and variance in offender residences across different levels of spatial aggregation. Three nested units are analysed simultaneously (and longitudinally) to explore the impact of using different spatial scales, opening prospect for a comparison with existing findings from crime concentration literature. Methods Data is utilized from West Midlands Police Force, containing the locations of residence for all known offenders in Birmingham between the years 2006 and 2016. Resident locations are aggregated to 3223 Output Areas (OA), nested within 639 Lower Super Output Areas (LSOA), further nested within 132 Middle Super Output Areas (MSOA). Descriptive and model-based statistics are deployed to replicate a recent study for crime events (Steenbeek \& Weisburd, 2016). Results In contrast to the crime concentration literature, the results indicate that most variance $(\sim 50 \%)$ in offender residence concentrations is attributable to the largest spatial scale (MSOA level). Output Areas, as the most fine-grained unit, capture approximately $39 \%$ of the variance, although this proportion increases during the study period at the expense of MSOA. Conclusions Findings suggest that the relationship between variance and scale when studying offender residences is not as clear-cut as it is for crimes. Larger units hold some merit (empirically and theoretically), but this is timedependent, opening up discussions on the role of urban development in determining the appropriateness of spatial scale.
\end{abstract}

Keywords: crime and place, offenders, geography, scale, hierarchical model.

Running head: Variability in offender residences across different spatial scales.

Corresponding author: Samuel Langton, Manchester Metropolitan University, Crime and Well-Being

Big Data Centre, Geoffrey Manton Building, Manchester, M16 6EB, United Kingdom.

Telephone: +44 (0)161 247 2000. Email: s.langton@mmu.ac.uk.

THIS IS THE PRE-PRINT VERSION OF THIS ARTICLE DATED 17 SEPTEMBER 2020.

$\dagger$ Department of Sociology, Manchester Metropolitan University, Manchester, United Kingdom.

$\ddagger$ Netherlands Institute for the Study of Crime and Law Enforcement, Amsterdam, Netherlands. 


\section{Introduction}

Recent years have seen a considerable rise in studies which utilize micro-geographic units of analysis to study spatial concentrations of crime and related phenomena such as emergency calls-for-service (Andresen et al., 2017; Gill et al., 2017; Hibdon et al., 2017; Weisburd et al., 2012). This surge of interest was, in part, driven by a series of influential descriptive studies which document the degree to which crime concentrates at micro-places in urban areas (e.g., Sherman et al., 1989; Pierce et al., 1988; Weisburd \& Green, 1995). In 2015, Weisburd synthesized much of these findings into the 'law of crime concentration', evidenced by the remarkable persistence of crime concentration at micro-places even amidst wider fluctuations in the absolute level of recorded crime (Weisburd, 2015). These 'global' descriptions of concentrations were augmented with endeavors to classify crime trajectories of micro-places (Andresen et al., 2017; Curman et al., 2015; Groff et al., 2010; Weisburd et al., 2004; Wheeler et al., 2016), identifying that a small number of micro-places, such as street segments, drive much of the macro-level trends in police-recorded crime (Andresen et al., 2017).

Acknowledging the micro-place as a theoretically appropriate and practically relevant scale to study crime, but also that street segments are nested within larger neighborhoods, recent efforts have sought to estimate the degree of concentration and variance attributable to different (nested) spatial scales simultaneously. ${ }^{1}$ Steenbeek \& Weisburd (2016) deployed descriptive statistics and a multilevel variance partition using street segments, neighborhoods and districts in The Hague, the Netherlands. They found that the largest proportion of variance was attributable to micro-places, suggesting that meso-level aggregations might mask underlying between-unit heterogeneity. This study inspired further investigations in Chicago (Schnell et al., 2017) and Stockholm (Gerell, 2017), which reported findings consistent with the idea that more 'action' was occurring at fine-grained micro spatial scales. These studies, in concert with the substantive demonstrations of longitudinal stability and hotspot policing strategies, served to further reinforce the notion that crime demanded investigation at highly localized geographic resolutions, while at the same time acknowledging the importance of larger neighborhoods, which have tended to be ignored in most 'crime and place' research.

That said, these recent investigations into the importance of fine-grained spatial scales and crime have neglected the complimentary strand of research which examines where known offenders live. This has occurred despite there being strong theoretical and empirical reasons for establishing the degree of concentration and variance in offender residences across different levels of aggregation. Rather than place-based opportunity structures, offender residence concentrations are thought to be determined by wider urban characteristics such as housing type (e.g. purpose-built public housing, owner-occupied properties) and residential redevelopment initiatives (Bottoms, 2018). Indeed, empirical studies have demonstrated that the causal mechanisms behind crimes and offender residence concentrations are distinct (Bruinsma et al., 2013) and likely to operate

\footnotetext{
${ }^{1}$ A related strand of methodological research does not use predefined units of analysis but aggregates micro-units into larger and larger units in order to find 'the appropriate scale' for the problem at hand, e.g. Malleson et al. (2019).
} 
at different spatial scales (Ouimet, 2000). In this manner, the suitability of highly localized spatial scales, such as micro-places, in studying offender residence concentration, cannot be presumed. The present study harkens back to the original investigations of Shaw (1929) and Shaw \& McKay (1942), who extensively plotted point-level maps of known offender residence locations in Chicago. We present a systematic comparison of nested geographic units of analysis, as has been achieved in the 'crime and place' strand of literature, to investigate whether 'smaller is better' in terms spatial scale for offender residences.

This paper is structured as follows. First, we provide an overview of existing studies which have explored the use of different geographic units of analysis when studying the spatial distribution of offender residences and (more commonly) crime events. Secondly, we outline the analytical strategy for the present study, which replicates the methods deployed in a recent paper which systematically compared concentration and variance across spatial scales for crime (Steenbeek \& Weisburd, 2016). We do this using ten years of police-recorded data on known offender residences in Birmingham, a large metropolitan area in the West Midlands, UK, and three nested geographic scales. Findings are discussed in relation to the theoretical and empirical distinctions between offenders and crimes and the context of the study region. The paper draws to a close with some concluding remarks and proposals for future research.

\section{Spatial scale and offender residences}

Although recent years have seen a concerted effort to examine the impact of spatial scale when studying crime and related phenomena, in particular those of micro-level units, interest in the topic is by no means new. In fact, much of these discussions began in relation to offender residences (i.e. where offenders live) rather the offences (i.e. where crimes occur). Comprehensive reviews of the field have traced the history of these discussions back to the 19th Century, amidst the first writings on the geography of crime (Weisburd et al., 2008, 2012). The earliest investigations into the geographic distribution of criminality were conducted using large, regionwide aggregations in France, with the likes of Quetelet (1831) and Guerry (1833), but focus quickly turned to more localized spatial scales. This was largely due to the recognition that there was a high degree of variability in where crime occurred and where offenders lived, even within specific urban areas and regions. Henry Mayhew reported as such during his examination of society and crime in 19th Century London (Mayhew, 1851). He demonstrated this using 'micro-level' units of analysis, such as specific roads and buildings, albeit often using anecdotal and observational evidence, rather than statistics. Lodging houses in particular were identified as problematic, as they tended to house individuals who were criminally active. It became clear that the region-wide maps generated by Mayhew's predecessors (and often Mayhew himself) might be masking underlying variation occurring at more localized scales.

Soon after, John Glyde conducted a case study of criminal populations in Suffolk, a largely agricultural 
county in England (Glyde, 1856). Like Mayhew, Glyde provided a novel insight into concentrations of offenders, but did so using multiple levels of aggregation. Within Suffolk, the number of known offenders housed in each local area ('Union') varied considerably. But, even within these areas, Glyde found that each town and village was "not equally favorable or unfavorable" and that "extremes are sometimes met within the same district" (p. 103). In other words, by disaggregating data on offenders down to localized geographies, rather than the large regions, greater variability could be unmasked. Even amidst the earliest mapping of criminality researchers were clearly mindful of the benefits of selecting an appropriately small geographic unit of analysis. It is also noteworthy that Glyde focused on "the localities in which the criminals have resided" (p. 102, emphasis in original), rather than where crimes occurred. In doing so, he observed discrepancies between the two phenomena, noting that many offenders did not reside in the town where the offence took place. This was early evidence to suggest that the factors driving offenders to reside in particular areas differed from those determining where offences were committed.

It would be the Chicago School, some decades later, which would set a benchmark in the study of offenders at 'micro' spatial scales. Shaw (1929), in collaboration with colleagues, most notably Henry McKay (Shaw \& McKay, 1942), used point-level maps of known offender residence locations in Chicago, alongside arealevel aggregations constituting neighborhoods, to demonstrate the non-random distribution of criminality in urban areas. Their studies elaborated upon earlier work by Breckinridge \& Abbott (1916) which described and mapped the residential locations of young male offenders, also in Chicago. Both bodies of work were consistent with Mayhew's anecdotal reports and Glyde's descriptive statistics some years earlier, namely, that there was significant variability in offender residence concentrations, even within the same urban conurbation.

Although much of Shaw and McKay's work is recalled for their theoretical contributions and analysis at neighborhood aggregations, Shaw's maps of residential locations have been credited as the first American study to recognize the value in micro-scale geographies (Steenbeek \& Weisburd, 2016). The Chicago School would go on to inspire a number of notable works elsewhere. In Britain, a case study by Terence Morris in Croydon examined the spatial distribution of offender residences and crime simultaneously using maps at a resolution which detailed specific streets and buildings in an effort to test the relevance of Shaw's work outside the United States (Morris, 1957). Later, the spatial patterning of offenders and crimes would be examined in Sheffield, with some maps using pin-point locations much in the style of Shaw's early visualizations (Baldwin et al., 1976).

Nevertheless, in the decades following the contributions of the Chicago School, investigations into the spatial patterning of crime and offenders would be few and far between. This has largely been attributed to concerns over the ecological fallacy (Robinson, 1950) and a lack of suitable data (Weisburd et al., 2012). In the 1980s, a concerted effort was made to revive interest in offenders with a specific focus on 'meso' units such as communities and neighborhoods, e.g. Reiss (1986) and Bottoms \& Wiles (1986) in Communities and 
Crime (Reiss \& Tonry, 1986), but in general, focus had shifted towards the concentration of crime, rather than offenders, and in time, towards micro-places, rather than meso units of analysis.

\section{Spatial scale and the concentration of crime}

In 1989, Sherman et al. (1989) reported that $50 \%$ of dispatch calls to the police in Minneapolis could be attributed to just over $3 \%$ of street addresses and intersections. Around the same time, almost identical findings were being reported for street addresses in Boston (Pierce et al., 1988). Subsequently, a number of studies began reporting comparable statistics about the disproportionately large volume of crimes and emergency calls for police occurring in particular places (Farrell, 1995; Spelman, 1995; Weisburd \& Green, 1995). Since then, the merits of these micro spatial scales in studying crime have been demonstrated across themes of concentration (Weisburd, 2015), stability (Andresen et al., 2017), theoretical explanation (Taylor, 2015; Weisburd et al., 2014) and policing interventions (Andresen \& Weisburd, 2018). Investigations into the concentration of crime at micro-places have taken place in numerous countries, such as Italy (Favarin, 2018), South Africa (Breetzke \& Edelstein, 2019), Belgium (Hardyns et al., 2019; Vandeviver \& Steenbeek, 2019), Japan (Amemiya \& Ohyama, 2019), and Nigeria (Umar et al., 2020) to name just a few. ${ }^{2}$

These findings held significance across a number domains. Firstly, evidence that crime is concentrated in specific places, such as commercial stores, residential buildings and street segments, is consistent with theoretical expectations. A key contention of routine activities theory (Cohen \& Felson, 1979) is that crime occurs at locations where motivated offenders and suitable target converge, and where opportunities present themselves, even within the same community (Eck et al., 2000). Thus, one would expect variability in crime even within the same neighborhood, depending on the opportunity structure of the streets and buildings nested within it. Secondly, and relatedly, the observed concentration of crime at micro-places supported the drive for 'hotspot' policing interventions as an effective and resource-efficient method for reducing crime (Sherman \& Weisburd, 1995). With these policing tactics largely considered to generate favorable outcomes (Braga et al., 2012) the importance of the micro-place in tackling urban crime was cemented.

One criticism of many of these analyses is that they do not include 'traditional' units of analysis, such as neighborhoods or communities. They may, therefore, be overestimating the importance of the microgeographic units in the explanation of crime. After all, if the micro-places where most crime events happen are clustered in the same neighborhood(s), a neighborhood-based explanation for crime seems plausible. Recent years have seen efforts to systematically compare micro units of analysis to larger meso or macrolevel scales based on characteristics such as concentration and between-unit variability. In doing so, the extent to which there is heterogeneity between units can be quantified, and in turn, 'where the action' is

\footnotetext{
${ }^{2}$ These investigations have also spurred methodological research about how to best quantify the concentration of crime at micro-places (e.g. Bernasco \& Steenbeek, 2017; Curiel et al., 2018; Mohler et al., 2019).
} 
occurring can be identified. The ability to systematically and simultaneously compare concentration and variation between nested spatial scales marked a major advancement over existing studies which tended to use micro-level geographies in isolation.

Steenbeek \& Weisburd (2016) conducted such a longitudinal comparison across nested spatial scales in The Hague, the Netherlands. The authors used a multilevel variance partition to estimate variance at each level using stratified samples to account for the dependency between observations and the statistical assumption of a random sample. Findings indicated that on average $62 \%$ of total variance in crime was attributable to the micro-level, defined as street segments. The next largest unit, neighborhoods, captured only $6 \%$ of variance, and the largest unit defined as districts accounted for $32 \%$ on average. Findings certainly did not dismiss the importance of meso-level units, but by estimating between-unit variability at each scale, the authors were able to empirically demonstrate that most of the 'action' in crime was occurring between street segments. This was consistent with the idea that opportunity structures, and thus crime, can vary considerably across micro-places, and that meso units can thus mask underlying variation.

This study sparked a series of related studies elsewhere. Schnell et al. (2017) replicated their work using data on violent crime in Chicago. Once more, findings suggested that most variability (i.e. between-unit heterogeneity) could be attributed to the micro-level, with street segments accounting for around $59 \%$ of total variance. Like Steenbeek \& Weisburd (2016), the authors also found that the relationship between scale and between-unit heterogeneity was not linear. Rather, community areas, as the largest unit, accounted for more variance $(\sim 25 \%)$ than the smaller neighborhood clusters $(\sim 16 \%)$. In both studies, the proportion of variance attributable to street segments increased throughout the study period, suggesting that the mechanisms driving variability in crime are subject to change over time.

Gerell (2017) conducted a comparable investigation in Stockholm, Sweden. Intra-class correlation (ICC) estimates were used to quantify the degree of variability in arson crimes at different spatial scales. Rather than using street segments as micro-places, synthetic geographies were generated to approximate Output Areas in England (see Oberwittler \& Wikström, 2009). Once more, most heterogeneity was identified at the micro level. No significant differences were found between medium and large-sized meso aggregations. Interestingly, findings suggested that greater variability could be unmasked using real, administratively defined geographies compared to synthetic units. This points to the importance of well-defined boundaries, designed with consideration for social and physical characteristics on the ground, in determining "where the action is'. 


\section{Present study}

During these advances for crime, there has been little concerted effort to examine the spatial patterning of offender residences (including questions over geographic resolution), despite its relevance to crime concentration research (Bottoms, 2007). The surge of interest in the where (crime) rather than the who (offenders) was part of a wider shift in criminology brought about by concerns over offender-based approaches to tackling the crime problem (Weisburd et al., 2012). And yet, reasons for reviving interest in offender residences, and conducting examinations into variation and concentration at different spatial scales, are plentiful. Offender residences and crimes are distinct (but related) phenomena. Offenders tend to commit crime relatively close to where they reside, within their behavioral spaces (Brantingham \& Brantingham, 1984), and thus spatially proximate high offender rate areas are a key independent variable when seeking to explain variability in crime concentrations (Bottoms, 2017). As such, the factors underpinning where offenders reside is of paramount of interest, even to those occupied with describing and explaining the spatial patterning of crime.

At the same time, there are reasons to suspect that the causal mechanisms driving offender residence and crime concentrations are distinct, operating at different spatial scales (Bottoms, 2018). Whereas opportunity theories might be appropriate for explaining street-to-street variability in crime, the factors generating high offender rate areas are thought to manifest at much larger, meso-level aggregations. The most influential causal model for these so-called 'delinquency areas', social disorganization theory, brought to prominence with Shaw and McKay's (1942) work in Chicago, was hypothesised to operate among communities and neighborhoods, rather than streets and intersections. At the core of the process was economic deprivation. Inexpensive housing fostered areas characterised by high residential turnover and population heterogeneity, rendering communities unable to self-regulate and deter delinquent behaviour, especially among its youth (Bursik Jr, 1986; Kornhauser, 1978). With cheap housing and economic deprivation varying little between spatially-proximate streets, and instead characterizing larger geographic scales, the offender-generating processes of social disorganization were expected to operate at area-level 'zones' and communities.

Studies seeking to disentangle mechanisms by which offenders can be disproportionately 'generated' in certain urban areas via social interaction effects have also conducted analysis at the meso (rather than micro) level. Bernasco et al. (2017) found evidence in the Netherlands to indicate that the propensity of individuals to engage in criminal activity can be influenced by the proportion of known offenders residing in the same neighborhood. For instance, the authors speculated that the risk of becoming a victim of violent crime in a 'tough' neighborhood containing a high number of known criminals might be minimized if individuals themselves engage in violence. The causal mechanism was expected to operate at the neighborhood-level as a "locus of social interaction" between residents (p. 628). Livingston et al. (2014) found that individuals residing in Glasgow neighborhoods with a high density of prior offenders were more likely to later become 
active offenders themselves. They too justified the neighborhood as a theoretically appropriate spatial scale to study social interaction effects between offenders nested within the same community.

With these discussions in mind, we cannot presume that the merits of fine-grained spatial scales ('where the actions happens') detailed in the crime-strand of literature are directly transferable to offenders. In fact, it is plausible, if not likely, that the causal mechanisms underpinning the spatial patterning of offenders create an urban landscape in which there is a high degree of between-unit heterogeneity in offenders at the meso-level, with the micro-units nested within them remaining fairly homogeneous. Indeed, such a finding would align with expectations that "the location of offender residences is a topic not usually best studied on a truly microlocational level" (Bottoms, 2018, p. 142).

In summary, spatial criminologists appreciate the theoretical and methodological value of fine-grained geographic units as well as their clustering into larger spatial units such as neighborhoods, but systematic investigations of concentration and variation using nested units have only been conducted on police-recorded crime data. No such investigations have been undertaken for offenders, despite there being clear reasons for doing so. This study is a first step to fill this gap. We use geocoded police-recorded data on known offender residences over a 10-year period in Birmingham, England. Data is aggregated to three nested spatial scales, namely, Output Areas, Lower Super Output Areas, and Middle Super Output Areas. The nested feature of the dataset is comparable to existing studies which have sought to describe and measure variability and concentration in crime (Gerell, 2017; Schnell et al., 2017; Steenbeek \& Weisburd, 2016). With some modification given the characteristics of the data, the methods deployed mimic those conducted in The Hague (Steenbeek \& Weisburd, 2016), consisting of descriptive statistics, visualizations and a multilevel variance partition to quantify concentration and variability in offender residences over time. In doing so, we advance understanding into the impact of spatial scale when studying offender residences.

\subsection{Data and Methods}

\subsection{Police data}

This study uses geocoded police-recorded data containing the location (Easting-Northing coordinates) of known offender residences in the city of Birmingham, England, for the 10-year period 2006/07 to 2015/16. Each study year runs from 1 April to 31 March. Birmingham is the second-largest city in the United Kingdom (UK) with a population of around 1.1 million people. It sits at the centre of the West Midlands region, served by West Midlands Police Force. Birmingham has a disproportionately high number of deprived areas compared to the rest of England and is one of the most ethnically diverse in the country, with around $53 \%$ of the resident population identifying as White British (Wessendorf, 2019).

A number of challenges arise with offender data which demand careful consideration. Firstly, the defini- 
tion of an 'offender', although a commonly used term in academic and policing research, is not straightforward. Influential work in England has tended to define an offender as those convicted or cautioned during the study period (Baldwin et al., 1976), or more specifically, for a notifiable offences (Bottoms \& Wiles, 1986). Studies undertaken in Sweden have included those individuals for which there are "reasonable suspicions" (Wikstrom, 1991, p. 263). In the Netherlands, studies have used data on "suspects" for individuals "whose file has been sent to the public prosecutor" (Bruinsma et al., 2013, p. 949). Offender records kept by West Midlands Police included two relevant categories, namely, those identified as a defendant/offender and suspects. A decision was made to the use the category of defendant/offender, since these are individuals who have been allocated a clear-up code following a formal charge or caution. Henceforth, these individuals are simply referred to as 'offenders'.

Secondly, unlike police-recorded crimes, offender records are not necessarily discrete. A large volume of total crime can be attributed to a disproportionately small number of offenders. As such, the unique nominal reference associated with each offender in police records can be duplicated for the legitimate reason that the individual committed (and was linked to) multiple different crimes. This represents a problem when certain areas contain highly prolific offenders. A high offender count might simply be an artefact of individual(s) being apprehended by the police multiple times, whilst continuing to live in the same place, rather than reflecting the number of active criminals residing there. This poses a problem, because measures of 'offender residences' have tended to aim for a measure of the resident population known to be participating in criminal activity.

Here, we construct a measure of participation based on a set of criteria. Duplicate nominal references (i.e. multiple records for the same individual offender) are only counted more than once if the offender was known to have moved to a new area (defined as Output Area, described in the next section) within the same year. For instance, an offender identified for a crime in April, and recorded as such, would be counted again if they were identified for a separate offence in December, but were living at a property located in a different Output Area. This was done so as not to underestimate the prevalence rate of other areas. Should an individual be identified in the same manner, but recorded as still living in the same Output Area, the individual would only be counted once in any given year. This was to avoid over-inflation. We recognize that such decisions are up for debate, and sensitivity analysis was conducted to ensure that findings were not dictated by this decision, as detailed later.

With this definition in mind, the number of known offenders residing in Birmingham fell throughout the study period (see Figure 1). The absolute count declined from around 20,000 in 2006/07 to below 8,000 in 2015/16. This is somewhat unsurprising given the widespread fall in police-recorded crime during the same 10-year period. As such, the wider context of this study, as has been the case for countless longitudinal studies of crime concentration in recent years, is a decline in crime (Andresen et al., 2017), and in this case, 
known offenders.

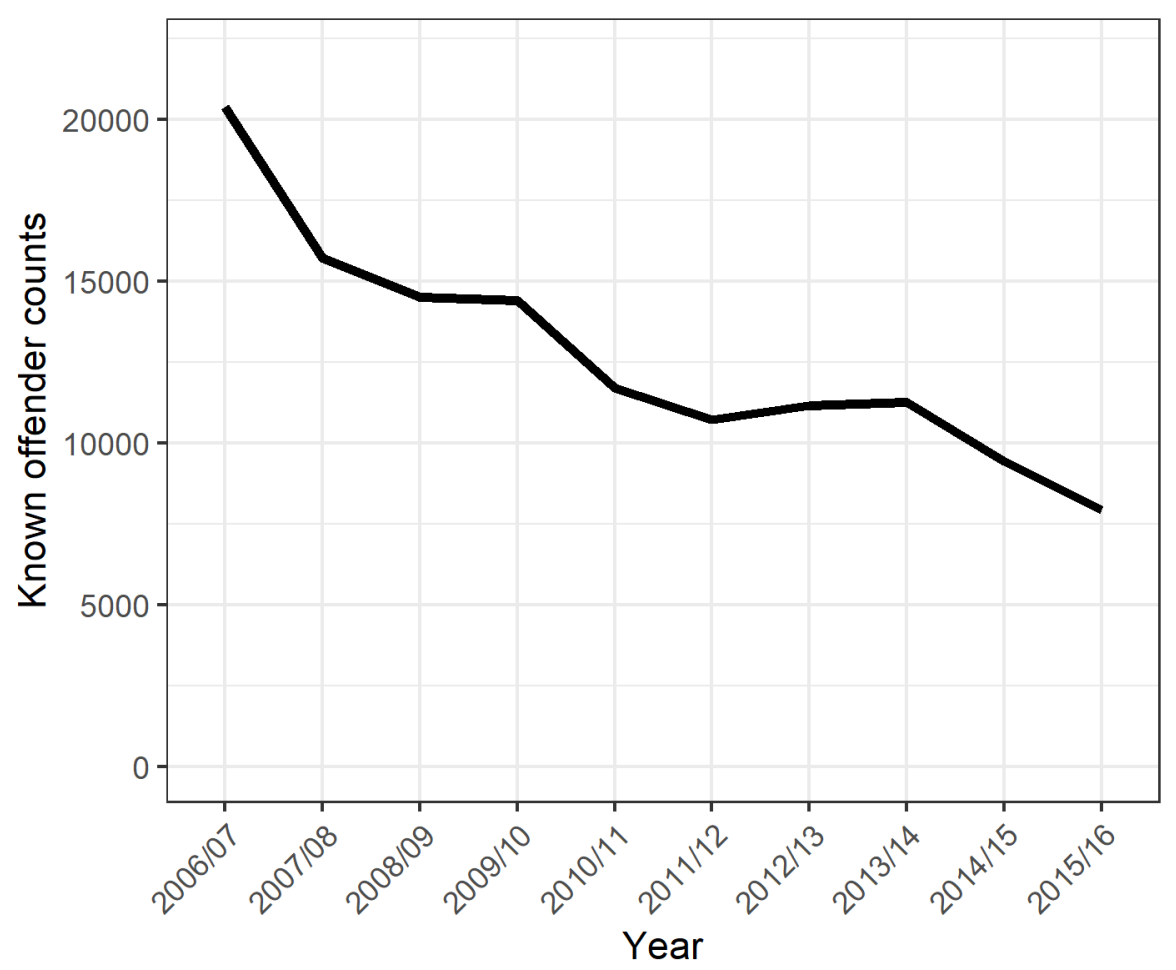

Figure 1: Citywide decline in known offenders in Birmingham.

Known offender records are included for all crime types. This is justified on a number of grounds. Firstly, offender data inevitably suffers from sparsity, especially when using fine-grained units of analysis. Not only do crimes have to be reported and recorded by the police, but an offender must be identified. In recent years, the nationwide detection rate during the study period was around 15\% (Home Office, 2018). We aggregate offenders irrespective of crime type to avoid having to exclude particular areas or specific crime types due to low counts. Crime types have been aggregated for reasons of sparsity in the equivalent crime literature (Steenbeek \& Weisburd, 2016). Given that this is the first endeavour to examine variability and concentration in offender residences across nested spatial scales, this also sets a baseline from which future research can be compared.

\subsection{Units of analysis}

Recent studies examining the impact of spatial scale on crime have adopted units which broadly resemble micro and meso-level levels of analysis across three levels (micro, small meso and large meso). In environmental criminology more broadly, authors have tended to discuss micro units in terms of street segments or properties, meso in terms of neighborhoods or communities, and macro in terms of counties or nations 
(Weisburd, 2015).

In this spirit, crime studies of spatial scale conducted in specific urban areas have mostly used street segments at the lowest (micro) level of aggregation (O'Brien, 2019; Schnell et al., 2017; Steenbeek \& Weisburd, 2016). Due to a lack of data at the street-level, the average number of residents has not been reported, but studies in the United States have stated that street segments tend to contain 99 street addresses (Weisburd et al., 2004). Gerell (2017)'s study in Stockholm used a synthetic area-based unit on the micro-level designed to approximate English Output Areas, which contain approximately 120 households (around 300 residents).

There has been considerable variation in the size of small and large meso units. For instance, the neighborhood unit used in Steenbeek and Weisburd's (2016) study in The Hague contained around 4,400 residents. The (larger) districts contained approximately 11,000 residents. Schnell et al.'s (2017) neighborhood clusters in Chicago contained an average of 8,000 residents, and community areas 36,000. In Stockholm, the smaller meso unit had an average of 1,000 residents, and the larger meso unit around 2,200 (Gerell, 2017).

In this study, we make use of administratively-defined census units, namely, Output Areas (OA), Lower Super Output Areas (LSOA) and Middle Super Output Areas (MSOA). Birmingham consists of 3223 OA, 639 LSOA and 132 MSOA. The availability of geocoded offender residence records permits the aggregation of counts to each scale using the measure of participation described earlier.

These units were considered appropriate for two main reasons. Firstly, the units are nested (OA within LSOA, LSOA within MSOA), which allows for the simultaneous comparison of variance across scales in the spirit of Steenbeek \& Weisburd (2016). Secondly, OA hold ontological significance as micro-places

in the English context. Birmingham is not comprised of a grid-based street network. Street segments vary considerably in length and resident population size. By contrast, OA are designed to contain socially homogeneous populations (Martin, 2002) and their boundaries reflect physical characteristics on the ground (Cockings et al., 2011). Boundaries also ensure relatively uniform resident population sizes, containing around 120 households (300 residents). As such, their residential scale and role as a meaningful behavioral settings are considered comparable to existing operationalizations of micro-places (e.g. Gerell, 2017). OA form the building blocks for LSOA and MSOA which contain approximately 2,000 and 10,000 residents respectively.

\subsection{Analytical strategy}

In alignment with the study being replicated (Steenbeek \& Weisburd, 2016) and those which have followed suit (e.g., Schnell et al., 2017), the analytical strategy has two principal stages. First, a series of descriptive statistics are reported which quantify and visualize the degree to which offender residences concentrate in Birmingham across the three respective spatial scales. Maps visualize the spatial distribution for OA, LSOA and MSOA respectively. We deploy hexograms (Harris et al., 2018) instead of mapping the original boundaries. These have been shown to maintain the spatial patterning (e.g. clustering) of areal-units (Langton \& 
Solymosi, 2019) whilst ensuring anonymity.

Percentage thresholds are then reported in tabular format to describe the proportion of total units (e.g. OA) containing $25 \%$ or $50 \%$ of total offenders, respectively. These statistics have been widely used in the offence-based literature and comprise the evidence-base for the law of crime concentration (Weisburd, 2015). Although these thresholds permit a straightforward comparison to existing findings, the thresholds are arbitrary. To visualize all possible combinations of percentage concentration, Lorenz curves can be plotted. These plot the cumulative proportion of crime against the cumulative proportion of spatial units, and demonstrate the degrees of crime concentration across spatial scales in isolation (e.g. Johnson, 2010). We plot Lorenz curves for OA, LSOA and MSOA units. The Gini coefficient is a quantified descriptive statistic of concentration based on the Lorenz curve (Gastwirth, 1972), which permits easier comparisons of concentration over time (Schnell et al., 2017; Steenbeek \& Weisburd, 2016). Measures of concentration based around the Gini coefficient have been specifically adapted for use in environmental criminology to account for data sparsity (Bernasco \& Steenbeek, 2017) and nested units (O’Brien, 2019). To compliment the Lorenz plots and and permit longitudinal comparisons, we also report Gini coefficients for each scale and year. ${ }^{3}$

The second stage uses linear mixed models (Raudenbush \& Bryk, 2002) to estimate the variance in offender residences attributable to each nested geographic unit of analysis (OA, LSOA, MSOA). This permits the estimation of the proportion of total variance at each level. We deploy a four-level model of years, nested within OA (micro), nested within LSOA (small meso) and MSOA (large meso). In alignment with existing studies (see Steenbeek \& Weisburd, 2016), we add a fixed effect of time to estimate the citywide trend. The slope of time can be allowed to vary across levels to permit the estimation of longitudinal changes in variance at each level.

The linear mixed models are deployed on random samples of units from the 'population' of geographic areas comprising Birmingham. This is justified on two main grounds which reflect those outlined by Steenbeek \& Weisburd (2016). Firstly, one of the assumptions underlying random effects models is that observations have been randomly drawn from a population. Running models using every single unit in Birmingham, which represents our population, would violate this assumption. Secondly, like crime, the geographic patterning of known offender residences is characterised by positive spatial autocorrelation (i.e. spatial clustering). Consequently, it is likely that observations with geographic proximity are somewhat dependent on one another and thus have correlated errors, violating another assumption of random effects models. Steenbeek \& Weisburd (2016) countered these issues by conducting analysis on stratified samples created by randomly drawing $25 \%$ of street segments (micro-level) from each neighborhood (small meso). The linear mixed models were then deployed on each sample, and mean of these estimates reported, along with the cumulative mean

\footnotetext{
${ }^{3}$ Mohler et al. (2019) provide a critique of the sparseness-adjusted Gini. The Gini coefficients in the present study are unaffected by their findings as the number of offenders is much higher than the number of smallest spatial units at each time point.
} 
of estimates as a function of the number of samples.

A comparable approach is adopted for this study using offender residence counts in Birmingham, with some modification. Here, we use a step-wise stratified sampling procedure for each spatial scale. First, 25\% of LSOAs are randomly sampled from within each MSOA, then from these LSOAs, a further $25 \%$ of OAs are drawn from within each LSOA, to comprise a single sample. This procedure was replicated 500 times to create 500 stratified samples for analysis, from which the mean estimates were computed. This step-wise procedure was used largely because positive spatial correlation was observed at all levels of analysis (OA, LSOA and MSOA), and thus it is insufficient to only account for this at the micro-level. A secondary benefit of this approach is computational efficiency.

Initial analyses on the raw dependent variable (offender residence counts), highlighted issues around the normality of residuals. Diagnostic plots indicated that the residuals in the dependent variable violated the assumption of normality. To rectify this, we used a $\log (\operatorname{count}+1)$ transformation, resulting in only mild violations of normality. This mimicked approaches taken in both Schnell et al. (2017) and Steenbeek \& Weisburd (2016). In previous studies, a control variable was added representing the length of street segments, since longer streets inevitably have greater opportunity for crime compared to shorter streets. By contrast, a natural denominator to calculate offender residence concentrations is the residential capacity of spatial units. Given that OA, LSOA and MSOA units are purposefully designed to be uniform by residential population, it is not necessary to include such a control variable (or population-standardized dependent variable) and thus, the log transformed count of offenders was used as the dependent variable.

\section{Results}

\subsection{Descriptive statistics}

\subsubsection{Offender residence concentration}

In alignment with existing research and the evidence-base surrounding the law of crime concentration (Weisburd, 2015), Table 1 reports the concentration of offender residences at $25 \%$ and $50 \%$ proportional thresholds, respectively. For instance, Table 1 reports that in the study year 2006/07, 25\% of known offenders resided in just $8.7 \%$ of OAs in Birmingham. For LSOAs, this figure was 11.4\%, and for MSOAs, 12.8\%. This suggests that known offender residence concentrations are greater using more fine-grained units. Interestingly, concentrations appear to increase over time. By the final study year, $25 \%$ of known offenders resided in $7 \%$ of OAs (down from 8.7\%). This is observed across all spatial scales and using both $25 \%$ and $50 \%$ thresholds. That said, there is clearly still some stability in the concentration of offender residences, even amidst the widespread decline in numbers known to West Midlands Police (see Figure 1). 
To capture the nuance in these concentration thresholds, and visualize other combinations of proportion, Figure 2 plots a Lorenz curve for the first study year. The line of perfect equality, resembling a scenario in which offenders are uniformly distributed across Birmingham (e.g. $50 \%$ of known offenders reside in $50 \%$ of OAs, and so on), serves as the reference point. The larger the area between the line of perfect equality and the Lorenz curve of each spatial scale, the greater the degree of concentration. As such, Figure 2 demonstrates that known offender residences tend to concentrate more at increasingly fine-grained units.

Table 1: Percentage of spatial units in which $25 \%$ and $50 \%$ of all known offenders reside, per year ending 31 March.

\begin{tabular}{rrrrrrrrrrrr}
\hline Unit & $06 / 07$ & $07 / 08$ & $08 / 09$ & $09 / 10$ & $10 / 11$ & $11 / 12$ & $12 / 13$ & $13 / 14$ & $14 / 15$ & $15 / 16$ \\
\hline \multicolumn{2}{c}{ 25\% of known offenders live in: } & & & & & & & \\
\multicolumn{2}{c}{ OA } & 8.69 & 8.63 & 8.66 & 9.18 & 8.78 & 8.47 & 8.16 & 7.76 & 7.45 & 6.98 \\
LSOA & 11.42 & 11.58 & 11.74 & 11.89 & 12.05 & 11.89 & 11.89 & 11.11 & 10.95 & 10.64 \\
MSOA & 12.88 & 12.88 & 12.88 & 12.12 & 12.88 & 12.88 & 12.12 & 12.12 & 12.12 & 12.12 \\
50\% of known offenders live in: & & & & & & & \\
OA & 22.31 & 22.03 & 22.22 & 23.12 & 22.22 & 21.69 & 21.50 & 20.88 & 20.57 & 19.42 \\
\multicolumn{2}{l}{ LSOA } & 28.01 & 27.86 & 28.33 & 28.64 & 28.79 & 28.48 & 28.33 & 27.54 & 27.54 & 26.76 \\
MSOA & 30.30 & 30.30 & 30.30 & 30.30 & 31.06 & 30.30 & 30.30 & 30.30 & 30.30 & 29.55 \\
\hline
\end{tabular}

To assist in the interpretation of these concentration statistics over time, Figure 3 visualizes the Gini coefficients for each study year, for each spatial scale. As noted, the Gini coefficient simply offers a quantified, singular descriptive statistic of concentration, calculated based on the areal ratios of each unit's Lorenz curve and the line of perfect equality. As such, the ordering of concentration by spatial scale mimics that of the thresholds and Lorenz curves. Now, however, we can observe the slight increase in concentration observed across each unit. For OAs, the Gini coefficient increased from around 0.45 in 2006/07 to 0.50 in 2015/17. For LSOA, the equivalent increase was smaller, increasing from 0.34 to 0.36. At the largest spatial scale, MSOA, the increase was only 0.01 (0.29 to 0.30). Not only are offender residences most concentrated at fine-grained (micro) units compared to meso-level aggregations, but longitudinal change in concentrations is also more evident when using such units. 


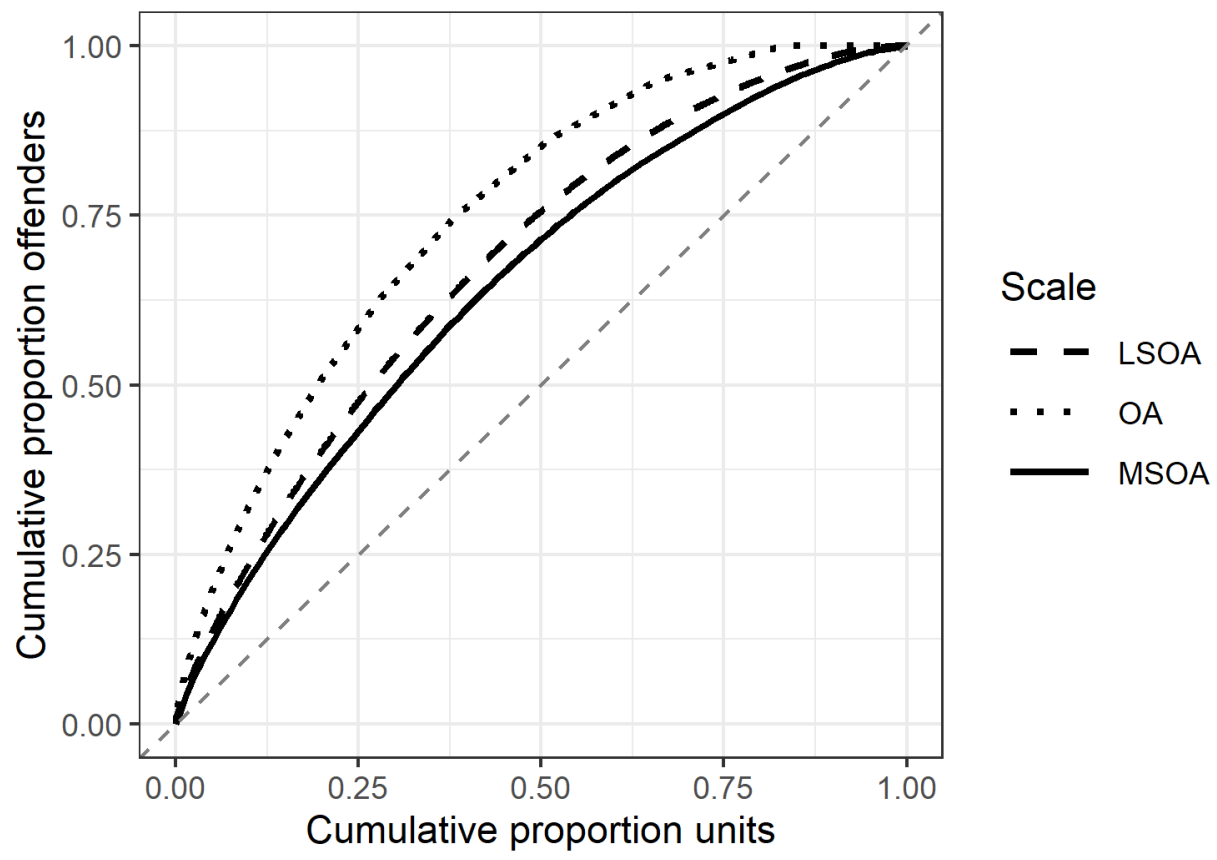

Figure 2: Lorenz curves for each spatial scale for 2006/07. Line of perfect equality included as a reference point.

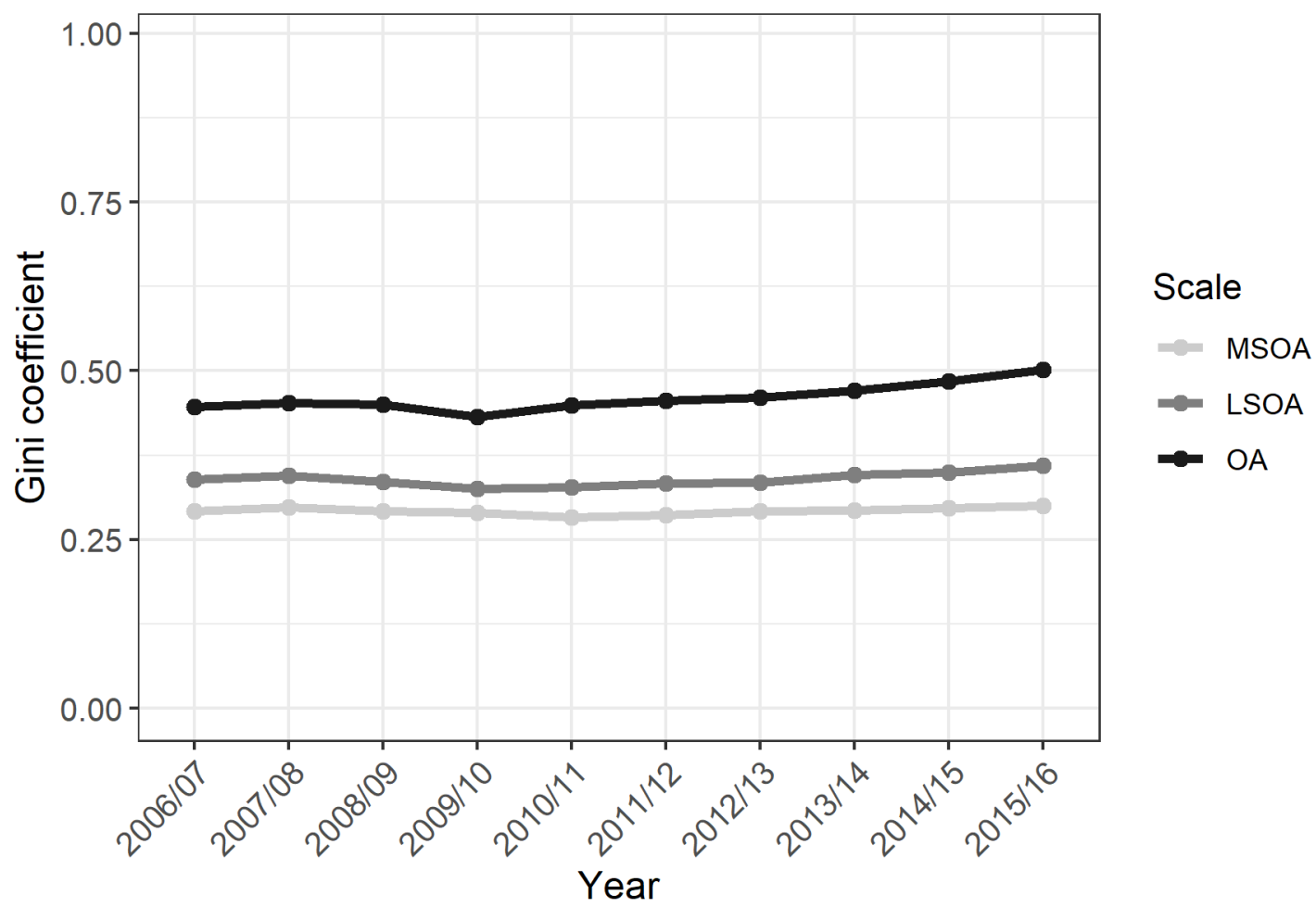

Figure 3: Gini coefficients for each spatial scale throughout the study period. 


\subsubsection{Spatial pattern of offenders residence concentration}

The spatial distribution of offender residence concentrations in Birmingham using OA, LSOA and MSOA levels of aggregation is visualized in Figure 4. As detailed in the analytical strategy, hexograms are deployed to maintain anonymity. Raw counts are categorized according to the Jenks-Fisher classification. Low-High labels are used rather than raw counts for reasons of privacy. A cursory glance of these maps reveals that offender residences, like crime, are non-uniformly distributed across Birmingham. Using MSOAs ( $=132)$, the largest level of aggregation, the spatial clustering of these concentrations emerge. The city centre itself is clearly visible due to the low number of known offenders residing in two neighboring MSOAs in the middle of the city. We see high clusters on the outskirts of the city centre to the north west, on the boundaries with Sandwell, a district neighboring Birmingham in the West Midlands. A number of MSOAs to the north and east of the city centre have high concentrations of known offender residences, often in isolation, and often surrounded by lower (but still relatively high) count areas.

Using LSOAs $(\mathrm{N}=639)$, the second-largest unit, we can disaggregate these patterns further. The map demonstrates once again that few known offenders reside in the city centre, but the use of this smaller meso unit highlights that even within the city centre, there is some variability. High count LSOAs are evident to the north west of the centre, in alignment with the MSOA map, but a number of high count areas now emerge to the north and north east. A number of LSOAs containing a large number of offender residences are dotted around the outer suburbs.

OAs, as the smallest micro unit $(\mathrm{N}=3223)$, further disaggregate the data. Again, the city centre is largely devoid of known offender residences. Instead, high count areas concentrate around the inner suburbs surrounding the centre. There is a high degree of positive spatial autocorrelation amongst these high offender count areas, with like-for-like classifications (according to the Jenks-Fisher breaks) tending to neighbor one another. One particular concentration of known offender residences in the north of the city emerges using OAs which was not evident using the meso scales of LSOA and MSOA. Although we are clearly getting more detail through the maps at lower aggregations such as OA, the high degree of spatial clustering suggests that meso units might not necessarily contain dissimilar (i.e. heterogeneous) micro units. 

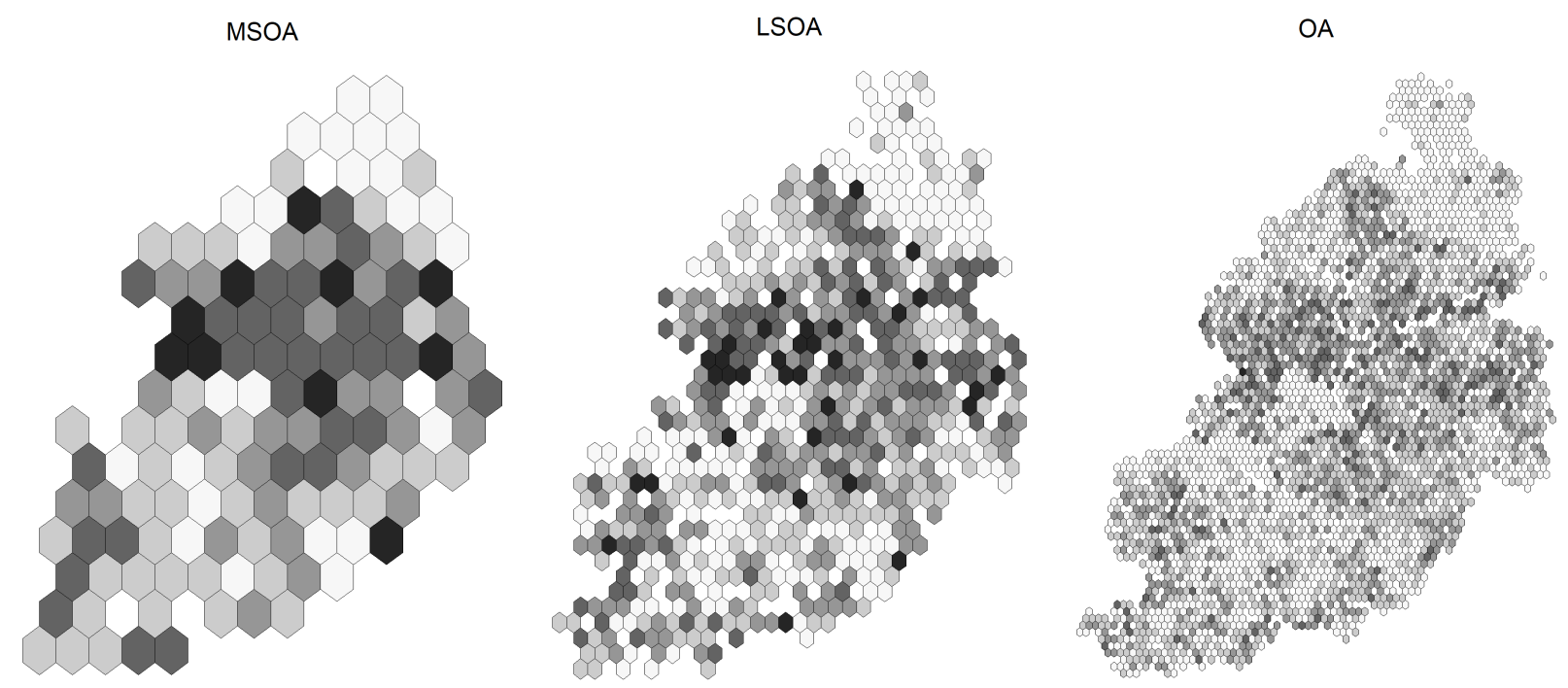

Low

High

Figure 4: Offender residence concentration counts in 2006/07 using hexograms (Harris et al., 2018) by spatial scale. Five low to high breaks computed using the Fisher-Jenks algorithm as per Schnell et al. (2017).

\subsection{Hierarchical Linear Models}

The descriptive statistics and visualizations reported so far have demonstrated the degree to which offender residences concentrate at each spatial scale. In this way, we have demonstrated that a disproportionately large number of known offenders in Birmingham reside in just a small number of areas within the city. The degree to which this is the case appears to vary by spatial scale, with smaller aggregations showing the highest concentration. These 'global' measures of concentration also appear relatively stable over time.

That said, these descriptives do not consider the nested structure of the units under examination, namely, OA (micro), LSOA (small meso) and MSOA (large meso). Using a linear mixed model, in replication of Steenbeek \& Weisburd (2016), we can estimate the degree of variability in these offender residence counts (i.e. between-unit heterogeneity) simultaneously. The four-level model thus has yearly time points, nested within OA, nested LSOA, nested with MSOA. A random slope of years allows the modelling of variance at each level as a function of time. The figures reported here are the mean estimates of the step-wise stratified sampling procedure, outlined earlier, using a $25 \%$ draw from each level.

The variance functions for each spatial scale are visualized in Figure 5. Notably, most variability in offender residences is attributable to the MSOA level, as the largest spatial scale. The quadratic shape of 
the OA variance function shows a decline, bottoming out around 2011/12, followed by an increase in the final few years. This change occurred amidst a decline in variance for both large (MSOA) and small (LSOA) meso-level units. For MSOA, this appears to be relatively linear, whereas for LSOA this decline begins to flatten out towards the end of the study period.

Figure 6 visualizes the proportion of total variance in offender residences attributable to each spatial scale. On average, $39 \%$ of total variance is attributable to OA, the smallest spatial scale. By contrast, MSOA, the largest spatial scale under examination, accounts for $49 \%$ of total variance on average, and LSOA accounts for around $12 \%$. In alignment with the variance functions in Figure 5, the proportional figures suggest that this variability is dynamic. At the MSOA level, the proportion of total variance fell from $50 \%$ in $2006 / 07$ to $45 \%$ in $2015 / 16$, whilst at OA level, the proportion increased from $39 \%$ to $44 \%$. LSOA remained relatively stable during this period.

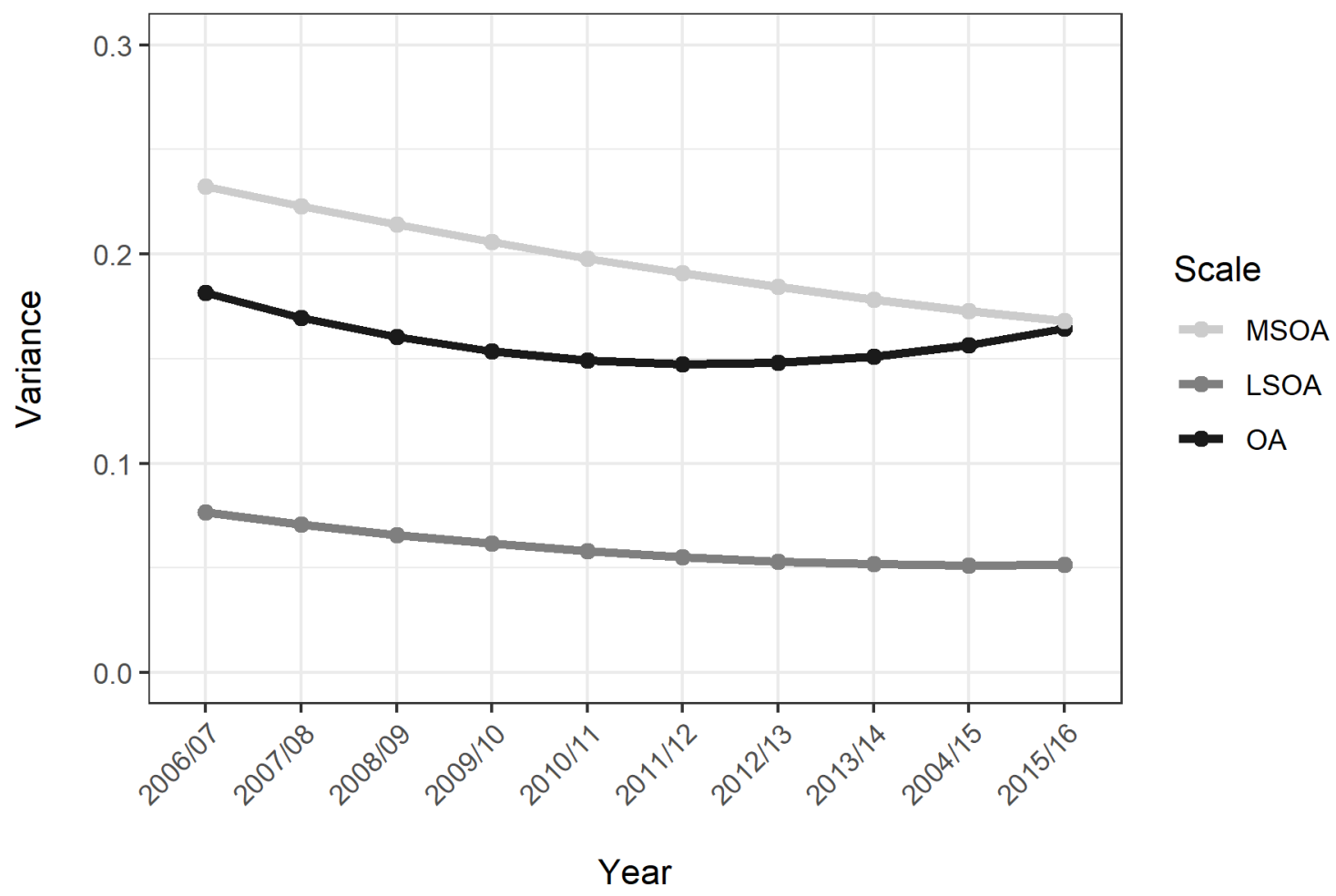

Figure 5: Variance functions for each spatial scale. 


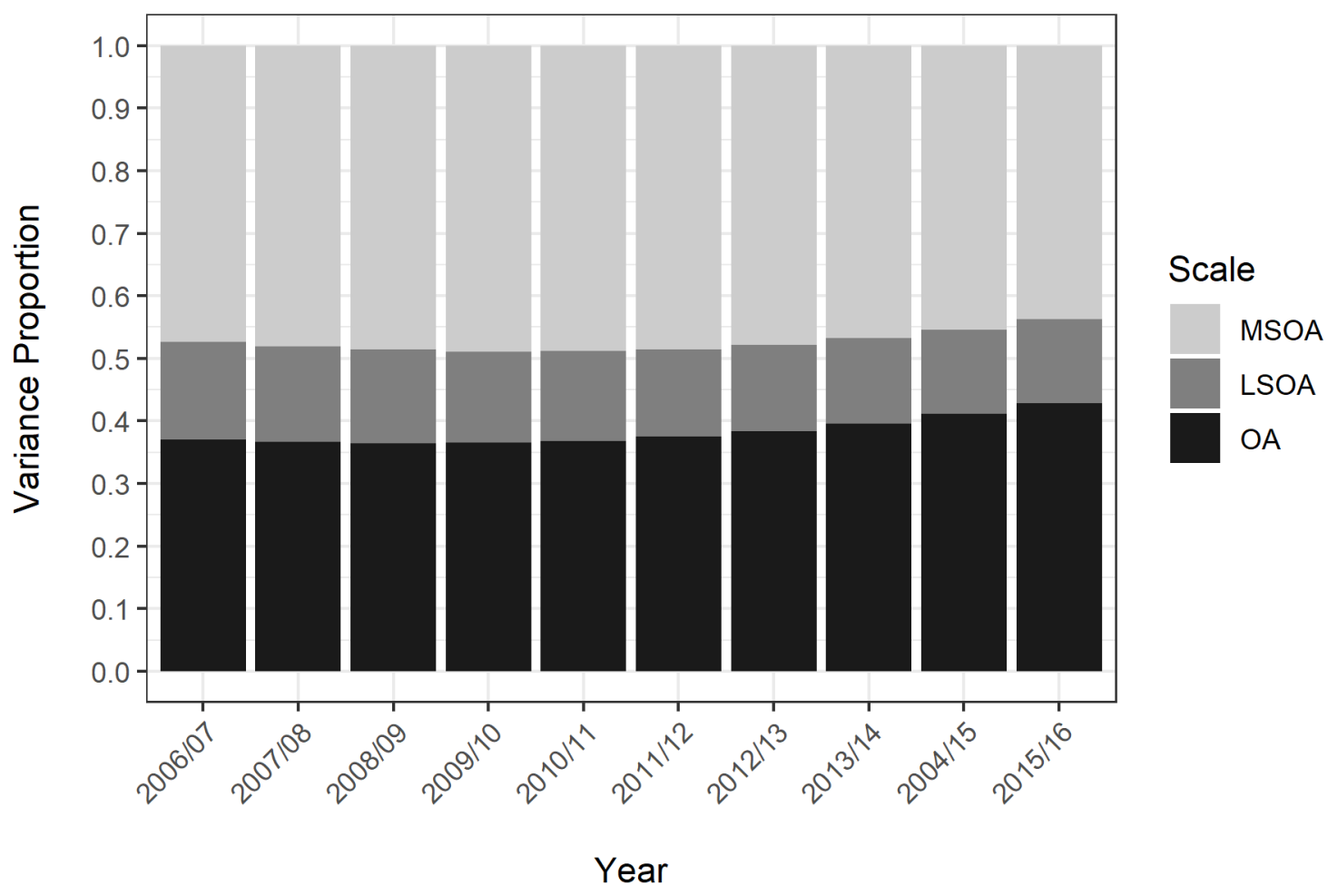

Figure 6: Proportion of total variance attributable to each spatial scale.

These findings from the linear mixed model highlight a number of points for discussion. Most variation in known offender residences appears to be occurring at the largest (meso) spatial scale, rather than at the micro-level. This indicates that there is greater heterogeneity between large, meso-level units compared to smaller, micro-level units, and represents an interesting departure from existing findings using police-recorded crime. We return to this point in the discussion.

\subsection{Sensitivity Analyses}

We generated a number of additional linear mixed models and descriptives to ensure that the variance partition findings were robust. Firstly, the cumulative mean of estimates obtained following each replication $(\mathrm{N}=500)$ were visualized (see Figure 7 in Appendix). This demonstrated that the mean estimates converged and became stable over time, confirming that 500 replications was sufficient, in alignment with Steenbeek \& Weisburd (2016).

Secondly, as detailed in the analytical strategy, we conducted the step-wise stratified sampling technique, whereby LSOAs were first sampled from within each MSOA, followed by OAs from within each LSOA, using different random samples sizes $(25 \%, 30 \%, 35 \%, 40 \%, 45 \%, 50 \%)$. The findings reported used data generated from sampling $25 \%$ of LSOAs from within each MSOA, and then $25 \%$ of OAs from within each remaining 
LSOA. Although larger percentages appeared to marginally decrease the estimated variance attributable to the MSOA, findings are robust to the percentage used for generating the random samples. Equivalent findings using a 50\% stratified sample are reported in the Appendix (see Figures 8 and 9), along with cumulative mean of variance estimates upon replication for each percentage sample (see Figure 7).

Thirdly, we investigated alternative operationalizations of the dependent variable. As noted, measuring the number of known offenders residing in particular areas is not straightforward. Offenders can appear multiple times in police-recorded data in scenarios where an individual has been linked to more than one crime, sometimes on multiple different occasions, over many years. As detailed, we constructed counts per area by only counting offenders more than once if the individual was known to have moved to a different OA within the same year. This permits some degree of flexibility. For instance, an offender known to reside within two different OAs in the same year nested within the same MSOA is only counted once in each OA, but twice at the MSOA-level. It is therefore not implausible that findings around variability could be an artefact of how the dependent variable was constructed.

To assess the sensitivity of findings to the counting criteria, we compared a number of otherwise identical models using different data sets in which (1) all offenders with duplicate records were removed, leaving only one-time offenders; (2) duplicate records were counted more than once if the offender was known to have moved house at all (i.e. just different Easting-Northing coordinates) within the same year, (3) duplicate records were counted more than once if the offender was known to have moved to a different LSOA within the same year; and (4) as per the previous option, but for MSOA. Re-conducting analyses using these different criteria did not have a significant impact on findings, suggesting that the results are robust to different operationalizations of the dependent variable.

\section{Conclusion and Discussion}

Using descriptive statistics on concentration, offenders appear to be most concentrated at fine-grained spatial scales. The relationship between scale and concentration is entirely consistent with existing findings examining crime: the smaller the geographic scale, the greater the degree of concentration. Computing Gini coefficients for each year demonstrates that these concentrations are also relatively stable over time, even amidst a citywide decline in the number of offenders known to police. These descriptive findings largely align with observations made about crime in The Hague (Steenbeek \& Weisburd, 2016) and Chicago (Schnell et al., 2017).

That said, by accounting for the nested structure of the data, the linear mixed models demonstrate that the degree of variability (between-unit heterogeneity) is greatest at the largest spatial scale (MSOA), which 
accounts for around $49 \%$ of the total variance in offender residences. ${ }^{4}$ By contrast, the smallest spatial scale (OA) accounts for only 39\%. This differs with findings for crime, which have tended to attribute most variance to the most fine-grained level of aggregation (Gerell, 2017; Schnell et al., 2017; Steenbeek \& Weisburd, 2016). In this manner, the micro-level is 'where the action' is happening for crime, but not for known offender residences.

The finding that most between-unit variability occurrs at the largest (meso) scale, rather than the micro, is consistent with the distinct theoretical mechanisms underpinning offenders. While crime-based opportunity theories operate among micro-level units such as street segments and addresses, the causal processes said to determine the spatial patterning of offender residences, such as social disorganization and social interaction between residents, are thought to manifest among meso-level neighborhood units (Bernasco et al., 2017; Livingston et al., 2014; Shaw \& McKay, 1942). Indeed, there is no requirement for the two phenomena to be studied at the same level of aggregation: calls for a re-examination of offender residences in space have been made with reference to meso-level units of analysis, whilst acknowledging the importance of micro-places when studying crime (Bottoms, 2018). Findings from this study certainly offer evidence to substantiate such claims.

That said, the between-unit heterogeneity at the micro-level (OA) appears to increase over time, at the expense of the large meso-level (MSOA). This is suggestive of a dynamic process by which the variability in offender residences is decreasing at the meso-level whilst increasing at the micro-level (becoming less homogeneous, more diverse). One potential avenue of investigation which could explain this change lies in the urban development which occurred in Birmingham during the study period. This involved large-scale regeneration projects, subsequently described as "planned gentrification" (Murie, 2018, p. 138), which may have redistributed offenders to specific areas of the city, increasing concentration and variability at localized scales.

Another potential explanation might originate from the manner in which the citywide fall in the number of offenders occurred (see Figure 1). Descriptive statistics suggest that the decline occurred non-uniformly across the city, with some areas falling quicker than others, and offender count trajectories shifting amongst one another over time (see Table 2 in Appendix). This may have been a result of policing resource allocation or community interventions, amongst other reasons. However it occurred, this instability is likely to have impacted on the degree of concentration and variance attributable to different spatial scales.

Further analysis would be required to unpick the underlying instability which appears to have occurred during the citywide decline. Longitudinal clustering methods have been deployed widely in the crime concentration literature to gauge the extent of instability at localized spatial scales, and identify which areas drive

\footnotetext{
${ }^{4}$ The observation that offenders concentrate most at OA level, but have most between-unit variability at MSOA level, is not contradictory. The Lorenz curve and Gini coefficient describe concentration at different levels of aggregation in isolation, whereas the linear mixed models estimate variability whilst accounting for the nested structure of the data.
} 
citywide trends (e.g. Andresen et al., 2017; Weisburd et al., 2012). Doing so would help pinpoint areas which may be responsible for the increased concentration and variance at OA-level. Explanatory models based on these cluster solutions, in the spirit of existing crime research (Weisburd et al., 2014), would also shed light on the causal mechanisms driving these trends. In this regard, there is already an established literature on explanatory mechanisms with reference to meso-level mechanisms (Bottoms, 2018).

The nature of police-recorded offender residence data also opens prospect for individual-level investigations into longitudinal stability. Unlike police crime records, which are discrete (i.e. there is only one record of each, geocoded to a specific location), offenders might appear multiple times in police records over the course of a 10-year period. Each time, their residential address is recorded. Of all the unique offenders identified by West Midlands Police during the study period, around 14,000 were known to have moved house to different $\mathrm{OA}$ between crimes. Tracking the individual-level residential population flows of these offenders might shed light on how and why concentration and variation at different spatial scales has shifted over time.

While police-recorded data on known offenders opens prospect for new avenues of research, answering recent calls for a revival in environmental criminology (Bottoms, 2018), its usage comes with caveats. Bias in police-recorded data on crimes has long been acknowledged. For instance, the willingness of victims to report crimes to the police varies according to characteristics such as age, employment, education and ethnicity (Hart \& Rennison, 2003). Such biases in the volume and consistency of crimes known to the police inevitably trickles down to determine the pool of offenders in police records. Contemporary research in the UK has also demonstrated that police forces may be unjustly targeting particular groups who then become 'usual suspects': individuals from deprived backgrounds, often young men, recycled through the youth justice system as "the deeds of their more affluent counterparts are overlooked" (McAra, 2017, p. 962). Policing practices that might lead to arrest, such as stop and search, have also been found to be exercised disproportionality on particular groups, such as ethnic minorities, even when controlling for other factors (Medina Ariza, 2014).

As a consequence, measures of offender residences constructed from police-recorded data are imperfect. It is likely that certain individuals (e.g. the 'usual suspects', ethnic minorities) are overrepresented in the data compared to the true offending population. Other groups of similarly active offenders may be underrepresented, such as those from a high socioeconomic background (McAra, 2017). The spatial nature of these residential characteristics might plausibly impact on the observed concentration and between-unit variability in known offenders. Future research seeking to replicate this study, as has been the case in the crime concentration literature, might consider making use of self-report offender surveys (e.g. Wikström et al., 2012) to rectify this shortcoming.

This study has sought to offer the first examination of concentration and variation in the spatial patterning of offender residences at multiple nested spatial scales. It has achieved this by replicating a key study in the 
crime-based literature (Steenbeek \& Weisburd, 2016), deploying descriptive (visual) statistics and a multilevel variance partition using 10-years of geocoded police records on known offender residences in Birmingham, England. Although there are some similarities with the crime-based literature, this study has highlighted some key differences which open up avenues for further investigation. Larger units clearly hold some merit, empirically and theoretically, when studying offender residences. There is greater between-unit variability at larger, meso-level spatial scales, which appears to be consistent with how offender-generating causal mechanisms are thought to manifest in urban areas. That said, the proportion of variance attributable to smaller, micro-level units has increased over time, at the expense of the meso-level, which is suggestive of a dynamic process. Further analysis is required using longitudinal clustering and individual-level residential population flows to disentangle this change, and identify the source of the shift in variance. 


\section{Appendix}
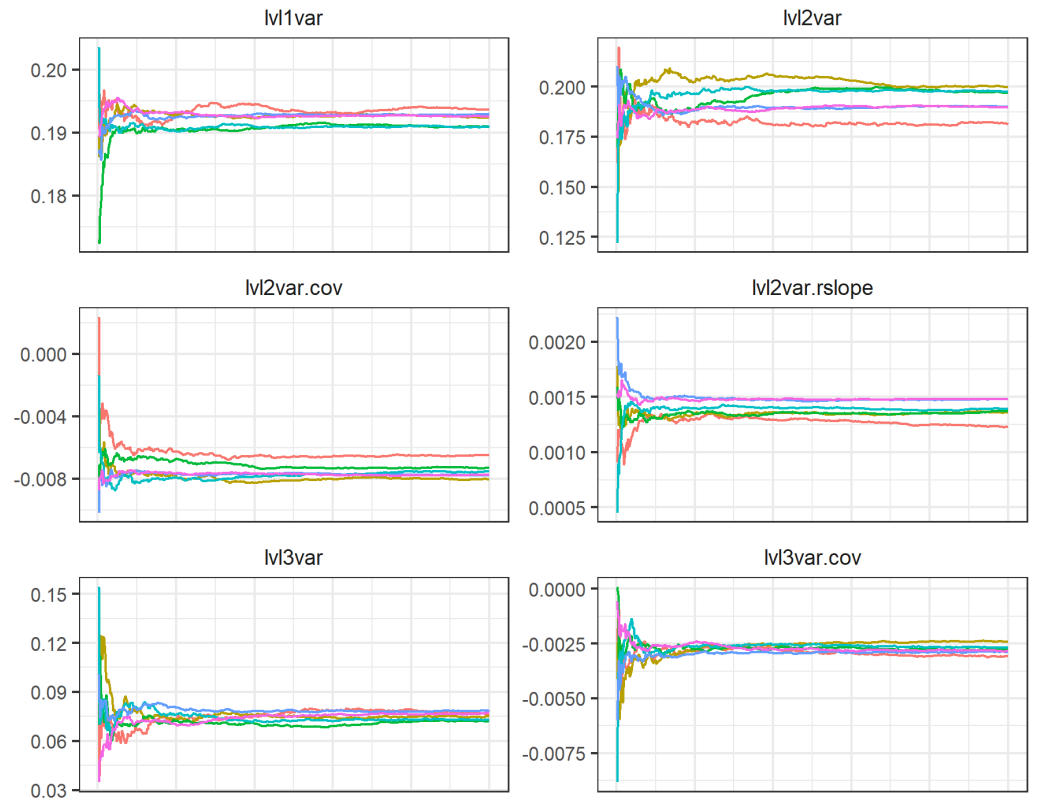

Ivl3var.cov
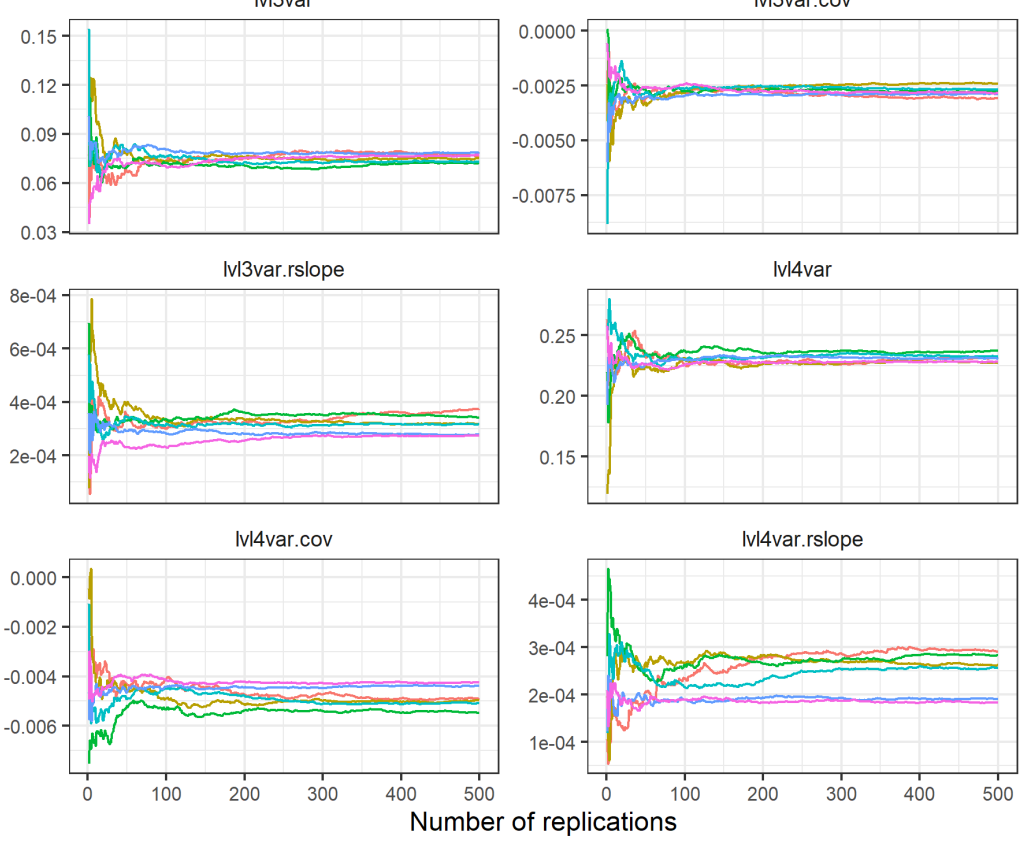

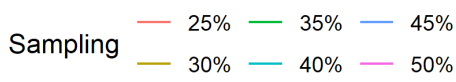

Figure 7: Cumulative mean of variance estimates using different stratified sampling percentages. 


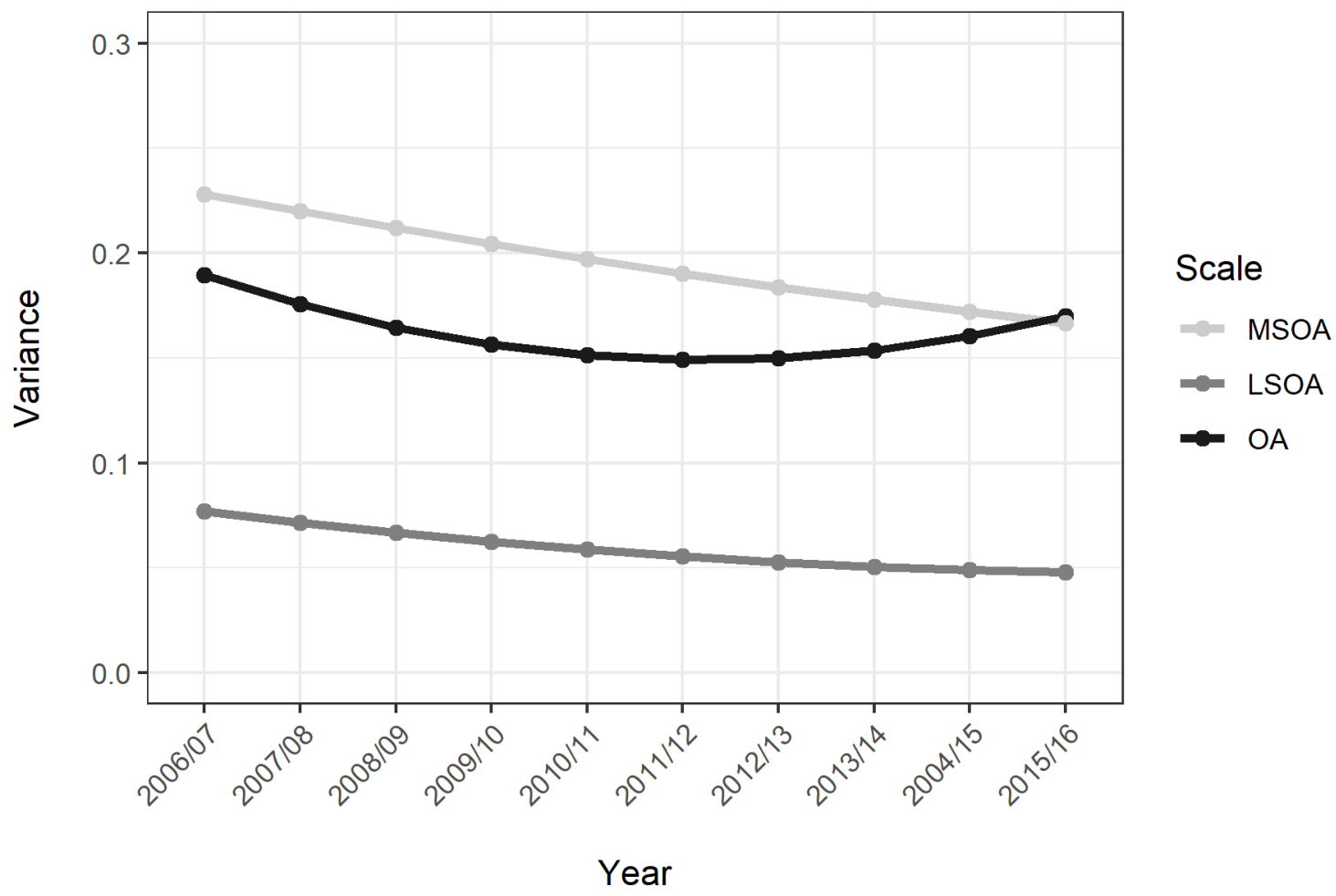

Figure 8: Variance functions for each spatial scale using $50 \%$ samples. 


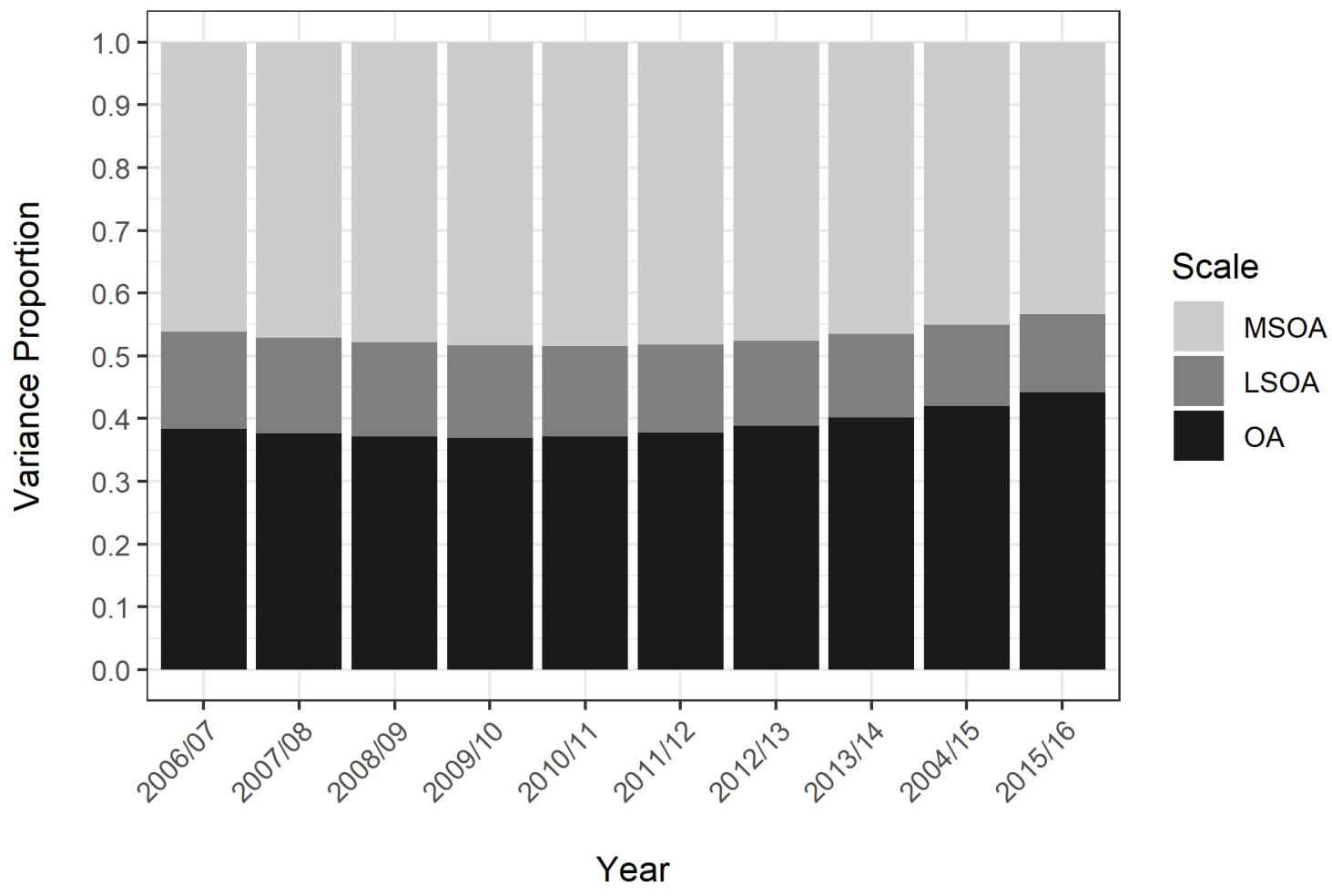

Figure 9: Proportion of total variance attributable to each spatial scale using $50 \%$ samples.

Table 2: Spearman's rank correlation at Output Area for known offender counts $(\mathrm{p}<0.05)$

\begin{tabular}{ccccccccccc}
\hline Year & $06 / 07$ & $07 / 08$ & $08 / 09$ & $09 / 10$ & $10 / 11$ & $11 / 12$ & $12 / 13$ & $13 / 14$ & $14 / 15$ & $15 / 16$ \\
\hline $06 / 07$ & 1.00 & 0.75 & 0.73 & 0.69 & 0.67 & 0.65 & 0.63 & 0.61 & 0.57 & 0.67 \\
$07 / 08$ & 0.75 & 1.00 & 0.75 & 0.69 & 0.69 & 0.67 & 0.66 & 0.64 & 0.59 & 0.62 \\
$08 / 09$ & 0.73 & 0.75 & 1.00 & 0.72 & 0.69 & 0.66 & 0.64 & 0.62 & 0.58 & 0.61 \\
$09 / 10$ & 0.69 & 0.69 & 0.72 & 1.00 & 0.70 & 0.66 & 0.65 & 0.61 & 0.58 & 0.60 \\
$10 / 11$ & 0.67 & 0.69 & 0.69 & 0.70 & 1.00 & 0.71 & 0.67 & 0.63 & 0.62 & 0.57 \\
$11 / 12$ & 0.65 & 0.67 & 0.66 & 0.66 & 0.71 & 1.00 & 0.75 & 0.71 & 0.68 & 0.55 \\
$12 / 13$ & 0.63 & 0.66 & 0.64 & 0.65 & 0.67 & 0.75 & 1.00 & 0.75 & 0.70 & 0.54 \\
$13 / 14$ & 0.61 & 0.64 & 0.62 & 0.61 & 0.63 & 0.71 & 0.75 & 1.00 & 0.75 & 0.50 \\
$14 / 15$ & 0.57 & 0.59 & 0.58 & 0.58 & 0.62 & 0.68 & 0.70 & 0.75 & 1.00 & 0.47 \\
$15 / 16$ & 0.67 & 0.62 & 0.61 & 0.60 & 0.57 & 0.55 & 0.54 & 0.50 & 0.47 & 1.00 \\
\hline
\end{tabular}




\section{References}

Amemiya, M., \& Ohyama, T. (2019). Toward a test of the "law of crime concentration" in japanese cities: A geographical crime analysis in tokyo and osaka. Crime Science, 8(1), 1-6.

Andresen, M. A., Curman, A. S., \& Linning, S. J. (2017). The trajectories of crime at places: Understanding the patterns of disaggregated crime types. Journal of Quantitative Criminology, 33(3), 427-449.

Andresen, M. A., \& Weisburd, D. (2018). Place-based policing: New directions, new challenges. Policing: An International Journal.

Baldwin, J., Bottoms, A. E., \& Walker, M. A. (1976). The urban criminal: A study in sheffield (Vol. 159). Taylor \& Francis.

Bernasco, W., Graaff, T. de, Rouwendal, J., \& Steenbeek, W. (2017). Social interactions and crime revisited: An investigation using individual offender data in dutch neighborhoods. Review of Economics and Statistics, 99(4), 622-636.

Bernasco, W., \& Steenbeek, W. (2017). More places than crimes: Implications for evaluating the law of crime concentration at place. Journal of Quantitative Criminology, 33(3), 451-467.

Bottoms, A. (2017). Crime specifics, offender residences, and social change: Developing the criminology of place. Jerusalem Review of Legal Studies, 15(1), 1-11.

Bottoms, A. (2018). The importance of high offender neighborhoods within environmental criminology. The Oxford Handbook of Environmental Criminology, 119.

Bottoms, A. E. (2007). Place, space, crime, and disorder. The Oxford Handbook of Criminology, 4, $528-574$.

Bottoms, A. E., \& Wiles, P. (1986). Housing tenure and residential community crime careers in britain. Crime and Justice, 8, 101-162.

Braga, A., Papachristos, A., \& Hureau, D. (2012). Hot spots policing effects on crime. Campbell Systematic Reviews, 8(1), 1-96.

Brantingham, P. J., \& Brantingham, P. L. (1984). Patterns in crime. Macmillan New York.

Breckinridge, S. P., \& Abbott, E. (1916). The delinquent child and the home. Survey Associates, Incorporated.

Breetzke, G. D., \& Edelstein, I. (2019). The spatial concentration and stability of crime in a south african township. Security Journal, 32(1), 63-78.

Bruinsma, G. J., Pauwels, L. J., Weerman, F. M., \& Bernasco, W. (2013). Social disorganization, social capital, collective efficacy and the spatial distribution of crime and offenders: An empirical test of six neighbourhood models for a dutch city. British Journal of Criminology, 53(5), 942-963.

Bursik Jr, R. J. (1986). Ecological stability and the dynamics of delinquency. Crime and Justice, 8 , 
$35-66$.

Cockings, S., Harfoot, A., Martin, D., \& Hornby, D. (2011). Maintaining existing zoning systems using automated zone-design techniques: Methods for creating the 2011 census output geographies for england and wales. Environment and Planning A, 43(10), 2399-2418.

Cohen, L. E., \& Felson, M. (1979). Social change and crime rate trends: A routine activity approach. American Sociological Review, 588-608.

Curiel, R. P., Delmar, S. C., \& Bishop, S. R. (2018). Measuring the distribution of crime and its concentration. Journal of Quantitative Criminology, 34(3), 775-803.

Curman, A. S., Andresen, M. A., \& Brantingham, P. J. (2015). Crime and place: A longitudinal examination of street segment patterns in vancouver, bc. Journal of Quantitative Criminology, 31(1), 127147.

Eck, J. E., Gersh, J. S., \& Taylor, C. (2000). Finding crime hot spots through repeat address mapping. Analyzing Crime Patterns: Frontiers of Practice, 49-64.

Farrell, G. (1995). Preventing repeat victimization. Crime and Justice, 19, 469-534.

Favarin, S. (2018). This must be the place (to commit a crime). Testing the law of crime concentration in milan, italy. European Journal of Criminology, 15(6), 702-729.

Gastwirth, J. L. (1972). The estimation of the lorenz curve and gini index. The Review of Economics and Statistics, 306-316.

Gerell, M. (2017). Smallest is better? The spatial distribution of arson and the modifiable areal unit problem. Journal of Quantitative Criminology, 33(2), 293-318.

Gill, C., Wooditch, A., \& Weisburd, D. (2017). Testing the "law of crime concentration at place" in a suburban setting: Implications for research and practice. Journal of Quantitative Criminology, 33(3), $519-545$.

Glyde, J. (1856). Localities of crime in suffolk. Journal of the Statistical Society of London, 19(2), $102-106$.

Groff, E. R., Weisburd, D., \& Yang, S.-M. (2010). Is it important to examine crime trends at a local "micro" level?: A longitudinal analysis of street to street variability in crime trajectories. Journal of Quantitative Criminology, 26(1), 7-32.

Guerry, A.-M. (1833). Essai sur la statistique morale de la france. Clearwater.

Hardyns, W., Snaphaan, T., \& Pauwels, L. J. (2019). Crime concentrations and micro places: An empirical test of the "law of crime concentration at places" in belgium. Australian $\&$ New Zealand Journal of Criminology, 52(3), 390-410.

Harris, R., Charlton, M., \& Brunsdon, C. (2018). Mapping the changing residential geography of white british secondary school children in england using visually balanced cartograms and hexograms. Journal of 
Maps, 14(1), 65-72.

Hart, T. C., \& Rennison, C. M. (2003). Reporting crime to the police, 1992-2000. US Department of Justice, Office of Justice Programs Washington, DC.

Hibdon, J., Telep, C. W., \& Groff, E. R. (2017). The concentration and stability of drug activity in seattle, washington using police and emergency medical services data. Journal of Quantitative Criminology, 33(3), 497-517.

Home Office. (2018). Crime outcomes in england and wales: Year ending march 2018. Statistical Bulletin HOSB 10/18.

Johnson, S. D. (2010). A brief history of the analysis of crime concentration. European Journal of Applied Mathematics, 21(4-5), 349-370.

Kornhauser, R. R. (1978). Social sources of delinquency: An appraisal of analytic models.

Langton, S. H., \& Solymosi, R. (2019). Cartograms, hexograms and regular grids: Minimising misrepresentation in spatial data visualisations. Environment and Planning B: Urban Analytics and City Science, 2399808319873923.

Livingston, M., Galster, G., Kearns, A., \& Bannister, J. (2014). Criminal neighbourhoods: Does the density of prior offenders in an area encourage others to commit crime? Environment and Planning A, 46(10), 2469-2488.

Malleson, N., Steenbeek, W., \& Andresen, M. A. (2019). Identifying the appropriate spatial resolution for the analysis of crime patterns. PloS One, 14(6), e0218324.

Martin, D. (2002). Geography for the 2001 census in england and wales. Population Trends, 108(7), 15.

Mayhew, H. (1851). London labour and the london poor: A cyclopaedia of the condition and earnings of those that will work, those that cannot work and those that will not work (Vol. 1). Cass.

McAra, L. (2017). Youth justice. In The Oxford handbook of criminology (pp. 938-966). Oxford University Press Oxford.

Medina Ariza, J. J. (2014). Police-initiated contacts: Young people, ethnicity, and the "usual suspects". Policing and Society, 24(2), 208-223.

Mohler, G., Brantingham, P. J., Carter, J., \& Short, M. B. (2019). Reducing bias in estimates for the law of crime concentration. Journal of Quantitative Criminology, 35(4), 747-765.

Morris, T. (1957). The criminal area: A study in social ecology. Routledge.

Murie, A. (2018). Decline and response? Lifecycle change and housing estates in birmingham, england. In Housing estates in europe (pp. 121-144). Springer, Cham.

Oberwittler, D., \& Wikström, P.-O. H. (2009). Why small is better: Advancing the study of the role of behavioral contexts in crime causation. In Putting crime in its place (pp. 35-59). Springer.

O'Brien, D. T. (2019). The action is everywhere, but greater at more localized spatial scales: Comparing 
concentrations of crime across addresses, streets, and neighborhoods. Journal of Research in Crime and Delinquency, 56(3), 339-377.

Ouimet, M. (2000). Aggregation bias in ecological research: How social disorganization and criminal opportunities shape the spatial distribution of juvenile delinquency in montreal. Canadian Journal of Criminology, 42, 135.

Pierce, G., Spaar, S., \& Briggs, L. (1988). The character of police work: Implications for the delivery of police service: Final report to the national institute of justice. Boston, MA: College of Criminal Justice, Northeastern University.

Quetelet, A. (1831). Research on the propensity to crime of different ages brussels: Hayez. Translated by Sawyer F. Test Sylvester. Cincinnati, OH: Anderson Publishing Co.

Raudenbush, S. W., \& Bryk, A. S. (2002). Hierarchical linear models: Applications and data analysis methods (Vol. 1). SAGE.

Reiss, A. J. (1986). Why are communities important in understanding crime? Crime and Justice, 8, $1-33$.

Reiss, A. J., \& Tonry, M. H. (1986). Communities and crime. University of Chicago Press.

Robinson, W. S. (1950). Ecological correlations and the behavior of individuals. American Sociological Review, 15, 351-357.

Schnell, C., Braga, A. A., \& Piza, E. L. (2017). The influence of community areas, neighborhood clusters, and street segments on the spatial variability of violent crime in chicago. Journal of Quantitative Criminology, 33(3), 469-496.

Shaw, C. R. (1929). Delinquency areas. University of Chicago Press.

Shaw, C. R., \& McKay, H. D. (1942). Juvenile delinquency and urban areas. University of Chicago Press.

Sherman, L. W., Gartin, P. R., \& Buerger, M. E. (1989). Hot spots of predatory crime: Routine activities and the criminology of place. Criminology, 27(1), 27-56.

Sherman, L. W., \& Weisburd, D. (1995). General deterrent effects of police patrol in crime "hot spots": A randomized, controlled trial. Justice Quarterly, 12(4), 625-648.

Spelman, W. (1995). Criminal careers of public places. Crime and Place: Crime Prevention Studies, 4 , $115-142$.

Steenbeek, W., \& Weisburd, D. (2016). Where the action is in crime? An examination of variability of crime across different spatial units in the hague, 2001-2009. Journal of Quantitative Criminology, 32(3), $449-469$.

Taylor, R. B. (2015). Community criminology: Fundamentals of spatial and temporal scaling, ecological indicators, and selectivity bias (Vol. 12). NYU Press.

Umar, F., Johnson, S. D., \& Cheshire, J. A. (2020). Assessing the spatial concentration of urban crime: 
An insight from nigeria. Journal of Quantitative Criminology, 1-20.

Vandeviver, C., \& Steenbeek, W. (2019). The (in) stability of residential burglary patterns on street segments: The case of antwerp, belgium 2005-2016. Journal of Quantitative Criminology, 35(1), 111-133.

Weisburd, D. (2015). The law of crime concentration and the criminology of place. Criminology, 53(2), $133-157$.

Weisburd, D., Bernasco, W., \& Bruinsma, G. (2008). Putting crime in its place. Springer.

Weisburd, D., Bushway, S., Lum, C., \& Yang, S.-M. (2004). Trajectories of crime at places: A longitudinal study of street segments in the city of seattle. Criminology, 42(2), 283-322.

Weisburd, D., \& Green, L. (1995). Policing drug hot spots: The jersey city drug market analysis experiment. Justice Quarterly, 12(4), 711-735.

Weisburd, D., Groff, E. R., \& Yang, S.-M. (2012). The criminology of place: Street segments and our understanding of the crime problem. Oxford University Press.

Weisburd, D., Groff, E. R., \& Yang, S.-M. (2014). Understanding and controlling hot spots of crime: The importance of formal and informal social controls. Prevention Science, 15(1), 31-43.

Wessendorf, S. (2019). Migrant belonging, social location and the neighbourhood: Recent migrants in east london and birmingham. Urban Studies, 56(1), 131-146.

Wheeler, A. P., Worden, R. E., \& McLean, S. J. (2016). Replicating group-based trajectory models of crime at micro-places in albany, ny. Journal of Quantitative Criminology, 32(4), 589-612.

Wikstrom, P. (1991). Urban crime, criminals and victims: The swedish experience in an anglo-american comparative perspective. New York.

Wikström, P.-O. H., Oberwittler, D., Treiber, K., \& Hardie, B. (2012). Breaking rules: The social and situational dynamics of young people's urban crime. OUP Oxford. 